\title{
Analysis of Building Life Cycle Energy Consumption Based on the Wall Insulation Materials
}

\author{
Lina Zhao ${ }^{1}$, Junlan Yang ${ }^{1}$ \\ ${ }^{1}$ Department of Energy and Safety Engineering, Tianjin Chengjian University, Tianjin 300384,China
}

Keywords: building envelop, insulation materials, energy consumption, pay back time.

\begin{abstract}
In this paper, an energy analysis model is set up in order to clarify the effect of insulation materials on the thermal performance and the energy consumption of building envelope. Three types of insulation materials commonly used in Germany including mineral fiber, polyurethane and vacuum insulation panel are chosen as the case study. The calculational results show that the energy consumption increases with the increasing of the insulation thickness while the heat losses decrease. So there exists an optimum thickness of the insulation to get the lowest total energy consumption. The ascending order of the total energy consumption of the three materials is mineral fiber, polyurethane and vacuum insulation panel. While their optimum insulation thicknesses show an reverse order with the increasing of heat transfer coefficients of the base envelope. Moreover, the energy payback time of each material is analyzed at the optimum thickness, which is greatly affected by the heat transfer coefficient of the base envelope. The longest pay back time is up to 21 years for the vacuum insulation panel if the base envelope heat transfer coefficient is as small as $0.2 \mathrm{~W} / \mathrm{m}^{2} . \mathrm{K}$.
\end{abstract}

\section{Introduction}

It is well known that the yearly energy cost of building is great all over the world. The global environmental deterioration has drawn attention of the local nations and international societies. In European Union, the construction and building sector is responsible for about $40 \%$ of the overall environmental burden. Most European governments have introduced new policy instruments, such as the European Community's energy performance directive for buildings (EPBD), in order to reduce the negative impacts of the building sector [1]. New requirements are put forward to the new or refurbished buildings as the interaction of society and environment is understood in depth.

There are some methods available for assessing the environmental impacts of materials and components. Life cycle assessment (LCA) is widely used because of the way to treat the framework, impact assessment and data quality integratedly [2]. Currently, many researchers are interested in the investigation of the building life cycle energy consumption and environmental impact during the extraction, processing and transportation of raw materials and the operation of building. Brendon [3] developed and implemented a life-cycle assessment for the building enclosures over a typical useful life in USA. Robin, etc. [4] proposed a life cycle energy analysis model to analyze the house energy consumption in Australia. Carol [5] studied the real efficiency of walls with high thickness insulation materials in Italy by the methodology of environmental balance. It was found that there is a minimal value above which it is unworthy to increase the thickness of wall components to obtain the advantage of lower energy consumption. Gu etc. [6] developed a life cycle assessment framework to evaluate building energy conservation and environment impact in Beijing, China. According to the life cycle cost analysis method, the model for thickness evaluation of economical insulation layer of external wall in Xi'an, China is put forward [7].

According to principles and frame work of LCA described in ISO 14040 and combing the policies and resources of China, an assessment method and corresponding target system was established, which considers both energy consumption and environment impact [8]. Zheng etc. [9] proposed the extenics theory and life cycle assessment for the assessment of building energy conservation. Tarantini etc. [10] applied life cycle assessment to wood windows showing how it supports the environmental criteria definition. Tsai etc. [11] adopted life cycle assessment (LCA) to assess $\mathrm{CO} 2$ emission costs and applied a mathematical programming approach to get maximize 
profits for construction companies with limited resources. Zabalza etc. [12] presented the state of the art of LCA application in buildings and the results of a LCA study comparing the most commonly used building materials with some new eco-materials. Huberman and Pearlmutter [13] analyzed both embodied and operational energy consumption in a climatically responsive building in the Negev desert region of southern Israel, comparing its actual material composition with a number of possible alternatives.

However, detailed life cycle energy studies are difficult and time consuming. Therefore, this paper describes a simplified approach to investigate the embodied energy of the building insulation materials and the heat transfer energy losses of the insulation in lifetime. Moreover, the optimum thickness of the insulation and the energy payback time are also studied.

\section{Framework of this study}

The discussed model is given as follow: LCA methodology is based on ISO 14040 and consists of four steps: defining the goal and scope, creating the life-cycle inventory, assessing the impact and finally interpreting the results [14]. This paper follows the LCA methodology to study the impact of building insulation materials which are widely used in Germany on the energy consumption caused by the heat losses of building envelope. Three types of insulation materials are chosen as the analysis object, including mineral fiber, polyurethane and vacuum insulation panel. The properties and production energy demand per unit mass of the three chosen insulation materials come from the previous work in Germany [15], as shown in Table 1. The lifetime of the building insulation materials is assumed to be 30 years. A unit area of envelope is chosen as the functional unit in order to determine the energy consumption of insulation materials and the heat transfer loss through the envelope.

\section{Calculation model}

In this study, the total energy consumption comprises two parts, one is the energy compensating the heat transfer losses of the building envelope, and the other is the energy for producing the insulation materials.

$$
\mathrm{E}_{\text {tot }}=E_{t}+E_{\text {in }}
$$

where, $E_{t o t}$ is the total primary energy, $\mathrm{kWh} / \mathrm{m}^{2} ; E_{t}$ the primary energy compensating the heat losses through the building envelope, $k W h / m^{2}$; and $E_{\text {in }}$ the primary energy for producing the insulation materials, $\mathrm{kWh} / \mathrm{m}^{2}$.

Annual heat loss is assumed to be constant during the lifetime of a building. So the entire energy demand by heat loss can be calculated by Eq. (2).

$$
\mathrm{E}_{t}=\frac{k \times G_{t} \times 24}{\eta_{t} \times 1000} \times N
$$

where, $k$ is the overall heat transfer coefficient of the building envelope as shown in Eq. (3), $W / m^{2} K ; G_{t}$ the annual heating days, $K d / a ; \mathrm{N}$ the lifetime of the insulation materials, and $\eta_{t}$ the efficiency of heating system.

$$
k=\frac{1}{\frac{1}{\alpha_{i}}+\frac{1}{k_{b w}}+\frac{\delta_{i n}}{\lambda_{i n}}+\frac{1}{\alpha_{o}}}
$$

where, ${ }^{\alpha_{i}}$ is the heat transfer coefficient of the internal surface convection, $W / m^{2} K$; ${ }^{\alpha_{o}}$ the heat transfer coefficient of the external surface convection, $W / m^{2} K$; $k_{b w}$ the overall heat transfer coefficient of the base envelope without insulation material, $W / m^{2} K$; $\delta_{\text {in }}$ the thickness of the insulation layer, $\mathrm{m}$; and $\lambda_{\text {in }}$ the thermal conductivity of the insulation material, $W / m K$.

For $1 \mathrm{~m} 2$ envelope surface, the total production energy consumption of insulation material is 
given by Eq. (4).

$$
E_{\text {in }}=\frac{\rho_{\text {in }} \times \delta_{\text {in }} \times P E_{\text {in }} \times 1000}{3600}
$$

where, $\rho_{\text {in }}$ is the density of the insulation material, $\mathrm{kg} / \mathrm{m}^{3} ; E_{\text {in }}$ the production energy demand per unit mass of the insulation material, $\mathrm{MJ} / \mathrm{kg}$.

According to Eq.(1), the total primary energy consumption can be rewritten as Eq. (5)

$\mathrm{E}_{\text {tot }}=\frac{\mathrm{G}_{\mathrm{t}} \times 24 \times \mathrm{N}}{1000 \times \eta_{\mathrm{t}} \times\left(\frac{1}{\alpha_{i}}+\frac{1}{k_{b w}}+\frac{\delta_{\text {in }}}{\lambda_{\text {in }}}+\frac{1}{\alpha_{o}}\right)}+\frac{\rho_{\text {in }} \times \delta_{\text {in }} \times P E_{\text {in }} \times 1000}{3600}$

when the total primary energy consumption of the insulation layer takes the minimum value, the corresponding thickness is defined as its optimum thickness. Under the optimum thickness of the insulation layer, the partial derivative of $E_{\text {tot }}$ in Eq. (5) with respect to $\delta_{\text {in }}$ should equal zero, i.e., $\partial E_{\text {tot }} / \partial \delta_{\text {in }}=0$. So the optimum thickness of the insulation layer can be obtained by Eq. (6).

$$
\delta_{\text {opt }}=\sqrt{\frac{3.6 \times G_{t} \times 24 \times N \times \lambda_{\text {in }}}{1000 \times \eta_{t} \times \rho_{\text {in }} \times P E_{\text {in }}}}-\lambda_{\text {in }} \times\left(\frac{1}{\alpha_{i}}+\frac{1}{k_{b w}}+\frac{1}{\alpha_{o}}\right)
$$

where, ${ }^{\delta_{\text {opt }}}$ is the optimum thickness of the insulation layer, $m$.

In addition, the second order derivative of $E_{\text {tot }}$ with respect to $\delta_{i n}$ is given by Eq. (7).

$$
\frac{\partial^{2} E_{\text {tot }}}{\partial \delta_{\text {in }}{ }^{2}}=\frac{2 \times G_{t} \times 24 \times N \times \lambda_{\text {in }}}{1000 \times \eta_{t} \times\left[\lambda_{\text {in }} \times\left(\frac{1}{\alpha_{i}}+\frac{1}{k_{b w}}+\frac{1}{\alpha_{o}}\right)+\delta_{\text {in }}\right]^{3}}
$$

It can be seen from Eq. (7) that the value of the second order derivative is greater than zero. So the optimum thickness of the insulation layer in Eq. (6) is the minimum value.

In fact, increasing the insulation materials will reduce the heat transfer through the building envelope, but more natural resources and energy are used for producing insulation materials. Therefore, it may take years more to pay back the cost.

The annual heat loss through the base envelope without insulation material is given as Eq. (8)

$$
\mathrm{Q}_{t b}=\frac{\mathrm{G}_{\mathrm{t}} \times 24}{1000 \times \eta_{t} \times\left(\frac{1}{\alpha_{i}}+\frac{1}{k_{b w}}+\frac{1}{\alpha_{o}}\right)}
$$

where, $Q_{t b}$ is the annual heat loss through the base envelope, $k W h / m^{2} a$.

The annual heat loss through the envelope with insulation material can be calculated by Eq. (9).

$\mathrm{Q}_{\text {tin }}=\frac{\mathrm{G}_{\mathrm{t}} \times 24}{1000 \times \eta_{\mathrm{t}} \times\left(\frac{1}{\alpha_{i}}+\frac{1}{k_{b w}}+\frac{\delta_{\text {in }}}{\lambda_{\text {in }}}+\frac{1}{\alpha_{o}}\right)}$

where, $Q_{t i n}$ is the annual heat loss through the envelope with insulation material, $\mathrm{kWh} / \mathrm{m}^{2} \cdot a$.

The Energy Payback Time (EPT) is defined as the ratio of the production energy consumption of the insulation material to the annual reduced heat loss due to addition of the insulation, as shown in Eq. (10)

$$
\mathrm{EPT}=\frac{\mathrm{E}_{\text {in }}}{Q_{t b}-Q_{\text {tin }}}
$$

where, EPT is the energy payback time, year.

In order to simplify the simulation, some assumptions are made: (1) The base envelope kbw is from 0.2 to $1.0 \mathrm{~W} /(\mathrm{m} 2 \mathrm{~K})$; (2) Gt is the heating days in Essen, a city in Germany, Gt=2273Kd; (3) $\delta$ in is from 0 to $0.5 \mathrm{~m}$; (4) $\eta \mathrm{t}$ is given as $90 \%$; (5) $\mathrm{N}$ is 30 years; (6) $1 / \alpha \mathrm{i}$ and $1 / \alpha \mathrm{o}$ are neglected.

\section{Results and analysis}

Here, the overall heat transfer coefficient of the base envelope kbw is assumed to be $1.0 \mathrm{~W} / \mathrm{m} 2 . \mathrm{K}$ and the energy consumptions for polyurethane over 30 years under different insulation thickness are 
calculated, as shown in Fig.1. It can be seen from figures that all the production energy consumptions rise linearly with increasing the insulation thickness and vacuum insulation panel has the largest rise. Whereas the heat losses of the envelope show an opposite trend. It can also be seen from Fig. 1 that the heat losses are very large if there is no insulation. Once the insulation material is applied, the heat losses drop abruptly with the increase of the insulation thickness. Fig.1 also shows that the total energy consumption firstly decreases to a minimal value at a certain thickness and then it increases with thickness. Hence, there exists an optimum insulation thickness corresponding to the lowest value of the total energy consumption.

Fig. 2 plots the total energy consumptions for the three insulation materials as $\mathrm{kbw}$ is $1.0 \mathrm{~W} / \mathrm{m} 2 . \mathrm{K}$. Obviously, the total energy consumption for the vacuum insulation panel is larger than that of the other two materials. With the increase of the insulation thickness, the gap becomes larger and larger. The total energy consumption for mineral fiber is the lowest while that of polyurethane being slightly larger. All the total energy consumption for the three insulation materials firstly decreases and then increases with the insulation thickness. Different materials have different optimum insulation thicknesses at which the total energy consumption is lowest.

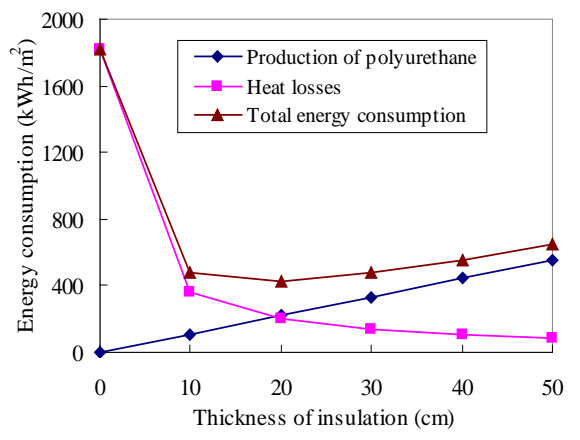

Fig.1: Energy consumption forpolyurethane

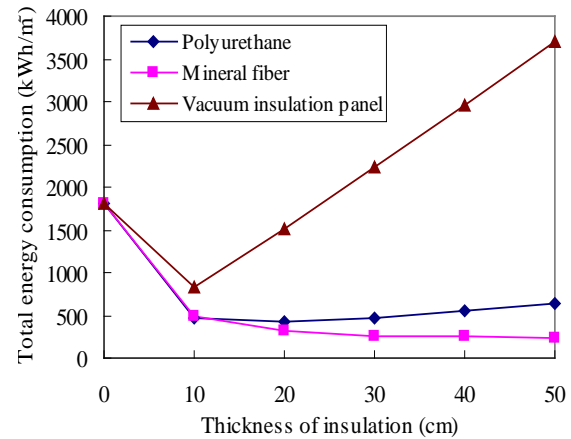

Fig.2: Comparison of total energy consumption

If the overall heat transfer coefficient of the base envelope kbw varies, the optimum thickness of the insulation varies accordingly, as shown in Fig. 3. The optimum insulation thicknesses for the three materials all increase slightly with the increase of kbw. It also can be found that the optimum thickness of the mineral fiber varied from 33 to $47 \mathrm{~cm}$ is the largest. While the optimum thickness of the vacuum insulation panel, from 1 to $3 \mathrm{~cm}$, is the lowest. It is attributed to the different production energy demands and properties of the materials, such as density and thermal conductivity, as shown in Table 1.

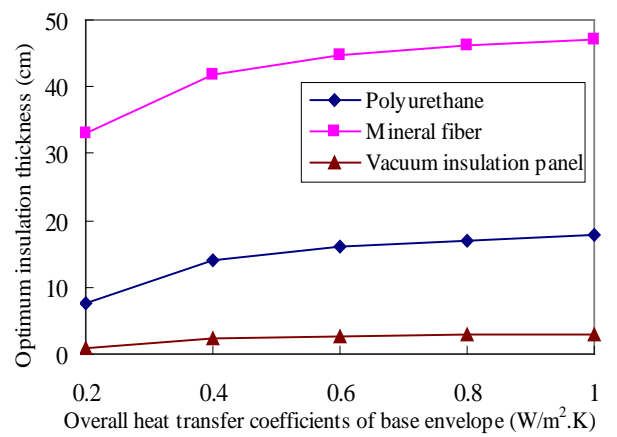

Fig.3: The optimum thickness of the insulation

Table 1: Properties and production energy demand of insulation materials [10]

\begin{tabular}{cccc}
\hline Materials & $\begin{array}{c}\text { Density } \\
\left(\mathrm{kg} / \mathrm{m}^{3}\right)\end{array}$ & $\begin{array}{c}\text { Thermal conductivity } \\
(\mathrm{W} / \mathrm{m} . \mathrm{K})\end{array}$ & $\begin{array}{c}\text { Production energy } \\
\text { demand } \\
(\mathrm{MJ} / \mathrm{kg})\end{array}$ \\
\hline Polyurethane & 30 & 0.025 & 134 \\
Mineral fiber & 25 & 0.035 & 36 \\
Vacuum insulation panel & 190 & 0.005 & 139.4 \\
\hline
\end{tabular}


The curves of the reduced heat losses versus kbw for each material, which is calculated at the optimum insulation thickness, are presented in Fig. 4. It can be seen that the reduced heat losses rise linearly with increasing the overall heat transfer coefficient of the base envelope. And the reduced heat loss for mineral fiber is larger than the others. The reduced heat losses for the polyurethane and the vacuum insulation panel are very close.

The curves of energy payback time versus kbw for each insulation material, which are calculated at the optimum insulation thickness, is plotted in Fig. 5. It is shown that when the heat transfer coefficient of the base envelope is reduced, the energy payback time increases quickly. For example, as kbw is $1.0 \mathrm{~W} / \mathrm{m} 2 \mathrm{~K}$, the EPTs for vacuum insulation panel, polyurethane and mineral fiber are 5,4 and 2 years, respectively. And when kbw is $0.2 \mathrm{~W} / \mathrm{m} 2 \mathrm{~K}$, the EPT of the three materials reach to 21, 19 and 10 years, respectively.

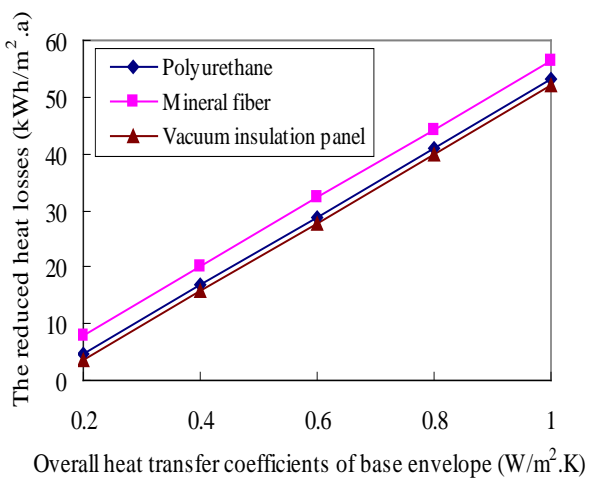

Fig.4: Change of the reduced heat losses

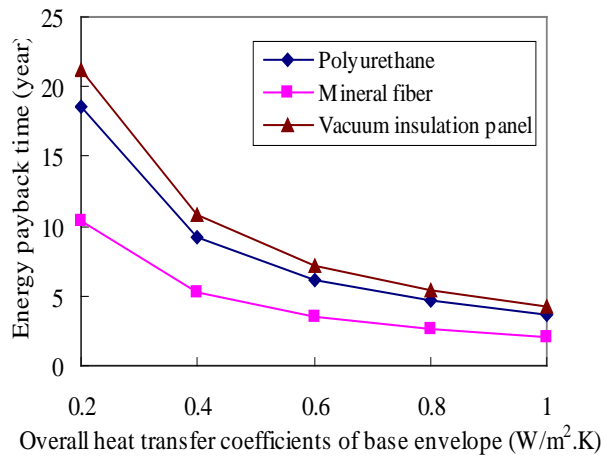

Fig.5: Change of the energy payback time

\section{Conclusions}

In this paper, the energy analysis model is set up to study the effect of three types of insulation materials in Germany. Due to different properties and production energy demands per unit mass for different materials, the total energy consumption is not the same. Such as, vacuum insulation panel is a high density and energy-intensive material, so its total energy consumption is the largest among the three materials, while mineral fiber is on the contrary. There is an optimum insulation thickness for each material to get the lowest total energy consumption. Vacuum insulation panel has the smallest optimum insulation thickness and mineral fiber has the largest. If the energy payback time is considered, which mainly depends on the heat transfer coefficients of the base envelope, the vacuum insulation panel needs the longest time. Thus, the total energy consumption and the envelope structure should be considered comprehensively when choosing insulation materials, or it will takc very long time to pay back the production energy consumption of the materials.

Furthermore, in order to ensure the sustainable development of the construction industry, the investigation of the resources consumption, environmental impact and economic investment of the materials should be carried out comprehensively and simultaneously.

\section{Acknowledgements}

This work was financially supported by the Natural Science Foundation of Tianjin, China under Grant 10JCYBJC08300.

Corresponding author: Lina Zhao, Tel: +86-15122770617, E-mail address: zhaolina627@163.com. 


\section{References}

[1] Mohamad MK, Phillip FG Banfill, Gillian F Menzies. Life-cycle assessment and the environmental impact of buildings: a Review. Sustainability,1,pp. 674-701,2009.

[2] Klöpffer, W. The role of SETAC in the development of LCA. Int. J. Life Cycle Assess,11(1), pp.116-122,2006.

[3] Brendon Burley. Life cycle assessment of operational energy expenses of buildingenvelope.http://www.engr.psu.edu/Symposium2006/papers/Burley.pdf, 2006.

[4] Robin D, Michael A, Selwyn T. Automating building life cycle energy assessment. International Council for Research and Innovation in Building and Construction CIB w78 conference. Aarhus School of Architecture, Denmark, pp.1-8,2002.

[5] Carol M. LCA of innovative high energy performance envelope. http://www. lcm2007.org/paper/ 318.pdf, 2007.

[6] Gu DJ, Gu LJ, Zhu YX. A life cycle assessment method for buildings. Proceedings of Building Simulation, Beijing, China, pp. 595-1600,2007.

[7] Shi JF, Li AG, Chen SL, etc. Research on the thickness of economical insulation layer of external wall in Xi'an. Architecture Technology \& Design , 9, pp.78-83,2008.

[8] Zhang Xu. Assessment Method of Building Energy Consumption Based on LCA. Refrigeration Air Conditioning \& Electric Power Machinery, 23(4), pp.1-3,27,2002.

[9] Zheng Guozhong, Jing Youyin, Huang Hongxia, Zhang Xutao, Gao Yuefen. Application of Life Cycle Assessment (LCA) and extenics theory for building energy conservation assessment.Energy ,34(11),pp.1870-1879, 2009.

[10] Tarantini Mario, Loprieno Arianna Dominici, Porta Pier Luigi. A life cycle approach to Green Public Procurement of building materials and elements: A case study on windows. Energy, 36(5), pp.2473-2482,2011.

[11] Tsai WH, Lin SJ, Liu JY, Lin WR, Lee KC. Incorporating life cycle assessments into building project decision-making: An energy consumption and $\mathrm{CO} 2$ emission perspective. Energy, 36(5), pp.3022-3029, 2011.

[12] Zabalza I, Aranda A, Scarpellini S, Díaz S. Life Cycle Assessment in Building Sector: State of the Art and Assessment of Environmental Impact for Building Materials. 1st International Exergy, Life Cycle Assessment, and Sustainability Workshop \& Symposium (ELCAS), NisyrosGreece,2009.

[13] Huberman N, Pearlmutter D. A life-cycle energy analysis of building materials in the Negev desert. Energy and Buildings,40(5), pp. 837-848,2008.

[14] ISO 14040 Environmental Management Life Cycle Assessment Principles and Framework. International Standards Organization: Brussels, Belgium, 2006.

[15] Siraki K. Bewertung von Wohngebäuden unter Lebenszyklusaspekten. Selbstverlag des Lehrstuhls für Energiesysteme und Energiewirtschaft, Ruhr-Universität Bochum, 2007. 